\title{
Neurocognitive and Self-efficacy Benefits of Cognitive Remediation in Schizophrenia: A Randomized Controlled Trial
}

\author{
Shayden D. Bryce, ${ }^{1,2}$ Susan L. Rossell, ${ }^{2,3,4}$ Stuart J. Lee, ${ }^{2,5}$ Richard J. Lawrence, ${ }^{1,2}$ Eric J. Tan, ${ }^{2,3,4}$ Sean P. Carruthers, ${ }^{2,3}$ \\ AND Jennie L. Ponsford ${ }^{1,6}$ \\ ${ }^{1}$ School of Psychological Sciences, Monash University, Clayton, VIC, Australia \\ ${ }^{2}$ Monash Alfred Psychiatry Research Centre, The Alfred and Monash University Central Clinical School, Melbourne, VIC, Australia \\ ${ }^{3}$ Centre for Mental Health, Swinburne University of Technology, Hawthorn, VIC, Australia \\ ${ }^{4}$ Psychiatry, St Vincent's Hospital, Fitzroy, VIC, Australia \\ ${ }^{5}$ Department of Psychiatry, Alfred Health, Melbourne, VIC, Australia \\ ${ }^{6}$ Monash-Epworth Rehabilitation Research Centre, Richmond, VIC, Australia \\ (Received August 14, 2017; Final Revision November 28, 2017; Accepted November 30, 2017; First Published OnLine January 21, 2018)
}

\begin{abstract}
Objectives: The aim of this study was to evaluate the impact of computer-assisted "drill-and-strategy" cognitive remediation (CR) for community-dwelling individuals with schizophrenia on cognition, everyday self-efficacy, and independent living skills. Methods: Fifty-six people with schizophrenia or schizoaffective disorder were randomized into CR or computer game (CG) playing (control), and offered twenty 1-hr individual sessions in a group setting over 10 weeks. Measures of cognition, psychopathology, self-efficacy, quality of life, and independent living skills were conducted at baseline, end-group and 3 months following intervention completion. Results: Forty-three participants completed at least 10 sessions and the end-group assessment. Linear mixed-effect analyses among completers demonstrated a significant interaction effect for global cognition favoring CR $(p=.028)$. CR-related cognitive improvement was sustained at 3-months follow-up. At end-group, 17 (77\%) CR completers showed a reliable improvement in at least one cognitive domain. A significant time effect was evident for self-efficacy $(p=.028)$ with both groups improving over time, but no significant interaction effect was observed. No significant effects were found for other study outcomes, including the functional measure. Conclusions: Computer-assisted drill-and-strategy CR in schizophrenia improved cognitive test performance, while participation in both CR and CG playing promoted enhancements in everyday self-efficacy. Changes in independent living skills did not appear to result from CR, however. Adjunctive psychosocial rehabilitation is likely necessary for improvements in real-world community functioning to be achieved. (JINS, 2018, 24, 549-562)
\end{abstract}

Keywords: psychosis, cognition, self-confidence, enhancement, training, rehabilitation.

\section{INTRODUCTION}

Cognitive dysfunction is an enduring feature of schizophrenia associated with low levels of occupation attainment, social engagement, and residential independence, even in the context of clinical remission (Bowie et al., 2008; Bowie, Reichenberg, Patterson, Heaton, \& Harvey, 2006; Fett et al., 2011; Green, Kern, \& Heaton, 2004; Harvey \& Strassnig, 2012; Rossell \& David, 1997). Appreciation of cognition as a strong contributor to psychosocial disability has led to the development of interventions specifically designed to target cognitive impairment. Cognitive remediation (CR) therapies

Correspondence and reprint requests to: Shayden Bryce, Level 4, 607 St Kilda Road, Melbourne, VIC, 3004, Australia. E-mail: shayden.bryce@ monash.edu are viewed as evidence-based methods capable of alleviating cognitive deficits in schizophrenia (Bryce, Sloan, Lee, Ponsford, \& Rossell, 2016; Grynszpan et al., 2011; McGurk, Twamley, Sitzer, McHugo, \& Mueser, 2007; Wykes, Huddy, Cella, McGurk, \& Czobor, 2011), and consequently, are being considered for use in mental health rehabilitation (Galletly et al., 2016). Nevertheless, there are limitations in studies to date that impact the strength of recommendations for clinical translation.

First, there have been few rigorous efficacy trials (Dixon et al., 2010). Only one-third of controlled studies met criteria for "good methodology" (i.e., 13/40) in one of the most comprehensive reviews of CR (Wykes et al., 2011). Some studies using active controls and blinded assessors have demonstrated poor transfer to untrained cognitive tasks following therapy (Dickinson et al., 2010; Gomar et al., 2015). 
Additionally, less than a third of controlled CR trials include follow-up assessments to examine sustainability of change (Paquin, Wilson, Cellard, Lecomte, \& Potvin, 2014; Wykes et al., 2011).

Trial quality and its impact on cognitive and functional enhancement in CR research, as well as potential changes in the proportion of high quality studies being produced, has not been systematically investigated since the 2011 meta-analysis by Wykes and colleagues. Nevertheless, many recently published CR reports lack comparison groups (Murthy et al., 2012; Pillet et al., 2015; Sharip et al., 2013) or primarily use treatment-as-usual controls (d'Amato et al., 2011; Hargreaves et al., 2015; Royer et al., 2012). These trials also inconsistently explore whether training-related improvements endure over time. Methodological limitations remain an area of ongoing discussion in the CR literature (McGurk et al., 2013).

Second, CR interventions are often embedded within broader therapeutic programs, which can include other psychological or vocational interventions that impact treatment outcome(s) (Bowie, McGurk, Mausbach, Patterson, \& Harvey, 2012; McGurk, Mueser, \& Pascaris, 2005; Vauth et al., 2005). Whilst combined approaches appear essential for optimizing functioning (Bowie et al., 2012; Wykes et al., 2011), non-specific effects derived from alternative therapies, such as social contact or therapeutic engagement, may account for some of the observed gains in treatment trials (Kurtz, Seltzer, Shagan, Thime, \& Wexler, 2007; McGurk et al., 2013).

Reviews that exclude studies integrating $\mathrm{CR}$ with vocational training provide less compelling support for the impact of CR on measures of cognition and psychosocial functioning relative to controls (NICE, 2009, 2014). Combining CR with strategy compensation (i.e., "drill-andstrategy" training) may represent an alternative means of supporting functional generalization in the absence of additional therapeutic programs; however, little is known about the extent to which these impact treatment success (McGurk et al., 2013; Penades et al., 2012).

Finally, the feasibility of community-based $\mathrm{CR}$ is a potential translational challenge. Of particular concern, some interventions demonstrating large effect sizes require 40-100 hr of training and high treatment intensities (e.g., 5 days/week) (Fisher, Holland, Merzenich, \& Vinogradov, 2009; Fisher, Holland, Subramaniam, \& Vinogradov, 2010; Penades et al., 2006). This may be problematic clinically as sustaining engagement over lengthy intervention periods is a potential barrier to psychosocial treatment use in schizophrenia (Parker, Foley, Walker, \& Dark, 2013).

There has been limited consideration of treatment outcomes beyond cognition, symptoms, and functional capacity or real-world behavior(s) in CR trials (Kern, Glynn, Horan, \& Marder, 2009; Kurtz, 2012). There is growing interest in the role of self-efficacy-beliefs regarding one's confidence of achieving success on a specific task (Bandura, 1977) —as a potential therapeutic target and process variable in cognitively enhancing treatment (Wykes \& Reeder, 2005;
Wykes \& Spaulding, 2011). CR purports to target cognitive skills underlying real-world functioning (Bowie et al., 2008; Wykes et al., 2012), but people with schizophrenia are also likely to have poor confidence in their ability to complete everyday tasks if they have experienced failure and low functional achievement (Medalia \& Richardson, 2005).

Self-efficacy has been associated with daily functioning in schizophrenia through its relationships with cognition, negative symptoms and functional capacity (Cardenas et al., 2013; Pratt, Mueser, Smith, \& Lu, 2005; Ventura et al., 2014). Nevertheless, while perceived competency in performing challenging cognitive exercises appears to improve following CR (Bowie, Grossman, Gupta, Holshausen, \& Best, 2017; Choi \& Medalia, 2010), there has been little investigation of whether self-efficacy concerning everyday living and social behaviors is specifically responsive to this type of intervention. This is despite self-efficacy representing an important component of recovery.

While infrequently examined, everyday self-efficacy has the potential to have a broader impact on community functions in schizophrenia (Cardenas et al., 2013). It could be responsive to cognitive enhancing interventions if participants learn strategies of functional relevance, have positively reinforcing learning experiences, achieve task mastery, observe peers succeeding on challenging tasks, and receive support as well as attributional and performance-based feedback (Bandura, 1977; Medalia \& Choi, 2010; Wykes \& Reeder, 2005).

\section{Aims of the Study}

This study aimed to evaluate the impact of a 20-session, computer-assisted, drill-and-strategy $\mathrm{CR}$ intervention on cognitive performance, everyday self-efficacy, and independent living skills in people with schizophrenia. The intervention was delivered in a group setting in the community and compared directly with a computer game (CG) playing condition. It was hypothesized that CR would produce greater improvements in global cognition, self-efficacy and independent living skills than the active control condition.

\section{METHODS}

\section{Design and Participants}

The trial was an assessor-blind randomized controlled trial with two independent interventions delivered in parallel. The study was approved by hospital and university human research ethics committees and reported in accordance with CONSORT guidelines (Schulz, Altman, Moher, \& the CONSORT group, 2010). Data described in this report were obtained in compliance with the Helsinki Declaration.

Individuals diagnosed with schizophrenia or schizoaffective disorder (American Psychiatric Association, 2000) were recruited from Melbourne-based mental health services in Victoria, Australia. Recruitment sites included community-based clinics 
or support services and residential rehabilitation programs. Participants (or their significant other) either contacted the research team directly in response to advertisement or staff involved in their care informed the team of potentially interested individuals made aware of the study aims.

Diagnoses were confirmed using the Mini International Neuropsychiatric Interview (v.5.0; Sheehan et al., 1998) and reviews of available clinical documentation. All participants gave written informed consent and were financially reimbursed for assessments only (\$40 AUD for baseline assessment; \$25 AUD each for end-assessment and follow-up). Recruitment and intervention groups were conducted between February 2015 and December 2016, with follow-up data collection extending until March 2017.

This study was designed to recruit 56 participants (28 per group). Factoring approximately $20 \%$ attrition, this would enable 44 to be included in the analysis, which would be sufficient to detect an anticipated medium effect $(f=0.25)$ for the interaction term using a $2 \times 3$ factor design with power of .95 and an alpha of .05. Participants were eligible if they had a diagnosis of schizophrenia or schizoaffective disorder, were aged 18-65, and had sufficient English language skills to communicate with the research team. Exclusion criteria included: (1) psychiatric hospitalization in the previous 2 months (to infer potential clinical stability); (2) estimated intellectual disability (scaled score $<70$ on the Wechsler Test of Adult Reading); (3) severe neurological or sensorimotor impairment producing a sustained impact on cognition; (4) substance dependence or electroconvulsive therapy in the previous 6 months; and (5) concurrent participation in another interventional research trial.

Following recruitment, consent and baseline assessment, participants were assigned to a group determined by a randomized sequence of CR or CG playing created using a random number generator. Randomization followed a blockbased schedule with between and within-block variability. A researcher (E.T.) independent of recruitment, intervention delivery, and data analysis managed this process.

Fifty-eight participants were recruited. Two participants were excluded at baseline due to intellectual disability and poor English language skills, resulting in a total randomized sample of 56 individuals. Of these participants, $98 \%$ were taking psychotropic medication, while $21 \%$ met MINI criteria for a depressive disorder, $20 \%$ met criteria for at least one anxiety disorder, and $9 \%$ met criteria for alcohol or other drug (cannabis or methamphetamine) abuse. Participants estimated as "borderline ill or less", "mildly ill", or "moderately ill or higher" was $33.3 \%, 37.1 \%$, and $29.6 \%$, respectively, based on PANSS total symptom scores (Leucht, 2014). Participant characteristics are summarized in Table 1. No significant between-group differences were observed for any variable in the eligible baseline sample $(N=56)$; however, there was a statistical trend for higher self-efficacy in controls $(p=.065)$. Participant progression through the study is illustrated in Figure 1.

Forty-three participants $(\mathrm{CR}=22 ; \mathrm{CG}=21)$ completed their allocated intervention. Seven $\mathrm{CR}$ and six $\mathrm{CG}$ playing participants withdrew during intervention with most either lost to follow-up or no longer interested in participating (see Figure 1). Attrition rates from baseline to end-treatment $(23 \%)$ were within ranges reported in other trials $(0-47.5 \%$; Wykes et al., 2011). Non-completers did not differ from completers in age, years of education, estimated IQ or medication dosage (all $p>.05$ ). Non-completers did, however, demonstrate significantly higher baseline self-efficacy $(p=.011)$ and negative symptoms $(p=.019)$ as well as trend-level differences suggestive of lower global cognitive function $(p=.064)$ when compared with completers. No significant baseline group differences were revealed when including intervention completers only (all $p>.05$; see supplementary data for completer characteristics). The total number of sessions attended by $\mathrm{CR}(M=12.95 ; S D=3.03)$ and CG $(M=12.86 ; S D=2.82)$ completers were equivalent $(p=.914)$.

\section{Measures}

\section{Primary outcome}

The primary outcome was global cognition, measured using the MATRICS Consensus Cognitive Battery (MCCB; Nuechterlein et al., 2008). The MCCB contains 10 standardized neuropsychological tasks that measure seven domains of cognition. Domain scores are used to generate a global composite ( $t$-score: $M=50 ; S D=10)$ derived from a normative sample of 300 adult controls (Kern et al., 2008).

\section{Secondary outcomes}

Everyday living skills were measured using the Independent Living Skills Survey-Self Report (ILSS-SR; Wallace, Liberman, Tauber, \& Wallace, 2000); a 70-item self-report measure designed for use in schizophrenia. The ILSS-SR asks participants whether they completed a range of everyday tasks within the last 30 days. Items are scored as Yes $(=1)$, No $(=0)$ or Not Applicable with the total averaged to yield a global functioning index. Scores closer to 1 indicate higher levels of independent functioning. The ILSS-SR has been rated via expert consensus as one of the best self-report measures of independent functioning in this population (Leifker, Patterson, Heaton, \& Harvey, 2011).

Task-specific self-efficacy was assessed using a 35-item version of the Revised Self-Efficacy Scale (RSES; Cardenas et al., 2013; McDermott, 1995). This self-report scale focuses on a participant's confidence in their ability to complete everyday living and social behaviors (e.g., "attend classes" and "make friends") (Cardenas et al., 2013). RSES items are rated on a 5-item scale ranging from 1 (not at all confident) to 5 (extremely confident). Higher scores represent higher levels of self-efficacy.

Psychiatric symptoms were operationalized using the traditional factor structure of the Positive and Negative Syndrome Scale (PANSS; Kay, Fiszbein, \& Opler, 1987). 
Table 1. Comparison of baseline demographic, clinical, and treatment characteristics for participants randomized to $\mathrm{CR}$ and $\mathrm{CG}$

\begin{tabular}{|c|c|c|c|}
\hline Variable & $\mathrm{CR}(n=29)$ & $\mathrm{CG}(n=27)$ & Test statistic $(p)$ \\
\hline \multicolumn{4}{|l|}{ Diagnosis, $n(\%)$} \\
\hline Schizophrenia & $23(79 \%)$ & $17(63 \%)$ & \multirow[t]{2}{*}{$\chi^{2}=1.83(.18)$} \\
\hline Schizoaffective disorder & $6(21 \%)$ & $10(37 \%)$ & \\
\hline Age, $M$ years $(S D)$ & $40.34(9.62)$ & $41.78(9.35)^{\mathrm{a}}$ & $t=-0.57(.58)$ \\
\hline Time since diagnosis, $M$ years $(S D)$ & $13.55(7.69)$ & $14.73(8.43)^{\mathrm{a}}$ & $t=-0.54(.59)$ \\
\hline \multicolumn{4}{|l|}{ Gender, $n(\%)$} \\
\hline Male & $19(66 \%)$ & $20(74 \%)$ & \multirow[t]{2}{*}{$\chi^{2}=0.48(.49)$} \\
\hline Female & $10(34 \%)$ & $7(26 \%)$ & \\
\hline Caucasian, $n(\%)$ & $26(90 \%)$ & $24(89 \%)$ & $\chi^{2}=0.01(.93)$ \\
\hline English first language, $n(\%)$ & $24(83 \%)$ & $25(93 \%)$ & $\chi^{2}=1.24(.27)$ \\
\hline Single / never married, $n(\%)$ & $25(86 \%)$ & $24(89 \%)$ & $\chi^{2}=0.09(.76)$ \\
\hline WTAR, $M$ scaled score $(S D)$ & $98.14(17.50)^{\mathrm{c}}$ & $98.08(11.59)^{\mathrm{a}}$ & $t=0.02(.99)$ \\
\hline Total education, $M$ years $(S D)$ & $13.45(3.19)$ & $12.81(2.42)$ & $t=0.83(.41)$ \\
\hline MCCB global, $M(S D)$ & $29.22(12.05)^{\mathrm{c}}$ & $31.11(11.67)$ & $t=-0.59(.56)$ \\
\hline ILSS-SR total, $M(S D)$ & $0.73(0.14)^{\mathrm{c}}$ & $0.73(0.12)$ & $t=-0.05(.96)$ \\
\hline RSES global, $M(S D)$ & $103.03(23.84)$ & $114.44(21.26)$ & $t=-1.89(.07)$ \\
\hline EUROHIS-QOL total, $M(S D)$ & $27.32(4.31)^{\mathrm{c}}$ & $27.04(5.46)$ & $t=0.22(.83)$ \\
\hline \multicolumn{4}{|l|}{ PANSS, $M(S D)$} \\
\hline Positive & $15.74(4.67)^{\mathrm{b}}$ & $15.19(5.17)$ & $t=0.41(.68)$ \\
\hline Negative & $17.15(7.04)^{\mathrm{b}}$ & $15.70(5.97)$ & $t=0.81(.42)$ \\
\hline General & $30.44(8.30)^{\mathrm{b}}$ & $31.22(7.49)$ & $t=-0.36(.72)$ \\
\hline Total & $63.33(16.06)^{\mathrm{b}}$ & $62.11(13.84)$ & $t=0.30(.77)$ \\
\hline \multicolumn{4}{|l|}{ Antipsychotic medication, $n(\%)$} \\
\hline Atypical only & $26(90 \%)$ & $21(78 \%)$ & $\chi^{2}=1.46(.23)$ \\
\hline Typical only & $2(7 \%)$ & $3(11 \%)$ & - \\
\hline Combination & $1(3 \%)$ & $2(7 \%)$ & - \\
\hline None & $0(0 \%)$ & $1(4 \%)$ & - \\
\hline CPZE, $M$ mg/day $(S D)$ & $738.45(510.54)$ & $666.35(454.63)$ & $t=0.56(.58)$ \\
\hline Antidepressant medication, $n(\%)$ & $6(21 \%)$ & $9(33 \%)$ & $\chi^{2}=0.03(.87)$ \\
\hline Mood stabilizers, $n(\%)$ & $8(28 \%)$ & $7(26 \%)$ & $\chi^{2}=0.18(.67)$ \\
\hline \multicolumn{4}{|l|}{ Concurrent psychopathology, $n(\%)$} \\
\hline Depressive disorder & $7(24 \%)$ & $5(19 \%)$ & $\chi^{2}=0.26(.61)$ \\
\hline Anxiety disorder & $5(17 \%)$ & $6(22 \%)$ & $\chi^{2}=0.22(.64)$ \\
\hline Alcohol and/or other drug abuse & $2(7 \%)^{\mathrm{c}}$ & $3(11 \%)$ & - \\
\hline
\end{tabular}

Note. ${ }^{\mathrm{a}} N=26 ;{ }^{\mathrm{b}} N=27 ;{ }^{\mathrm{c}} N=28$.

$\mathrm{CR}=$ Cognitive remediation; $\mathrm{CG}=$ computer games; $\mathrm{CPZE}=$ Chloropromazine equivalence (see Woods, 2003); EUROHIS-QOL $=$ European Health Interview Survey - Quality of Life; ILSS-SR = Independent Living Skills Survey - Self-Report; $M=$ mean; MCCB $=$ Matrics Consenus Cognitive Battery; PANSS = Positive and Negative Syptom Scale; RSES = Revised Self-Efficacy Scale; $S D=$ standard deviation; WTAR $=$ Weschler Test of Adult Reading.

Subjective quality of life was measured using the eight-item European Health Interview Survey (EUROHIS-QOL; Schmidt, Muhlan, \& Power, 2006). This scale targets physical, psychological, social, and environmental domains. Each item is rated on a 5-item scale ranging from 1 (very dissatisfied) to 5 (very satisfied). Higher scores represent better quality of life.

\section{Procedure}

Trained research staff, blinded to participant group allocation, conducted assessments at three time points: (1) baseline; (2) end-group; and (3) 3-months post-intervention. Assessors held Bachelors to Professorial level qualifications in psychology. Each outcome measure was administered at every time point. Participants were asked about alcohol or other drug use in the $24 \mathrm{hr}$ preceding their assessments to screen for potential acute intoxication. On average, groups commenced within 2 weeks of participant baseline assessments $(M=10.55$ days; $S D=7.38)$, while end assessments were completed within 1 week of group completion $(M=5.28$ days; $S D=2.99$ ).

\section{Interventions}

All participants were offered twenty 1-hr computer sessions, delivered in the community twice weekly in groups of two to five people (median =3) over 10 weeks. Participants completed their own computer exercises individually; however, sharing aspects of the learning experience was 


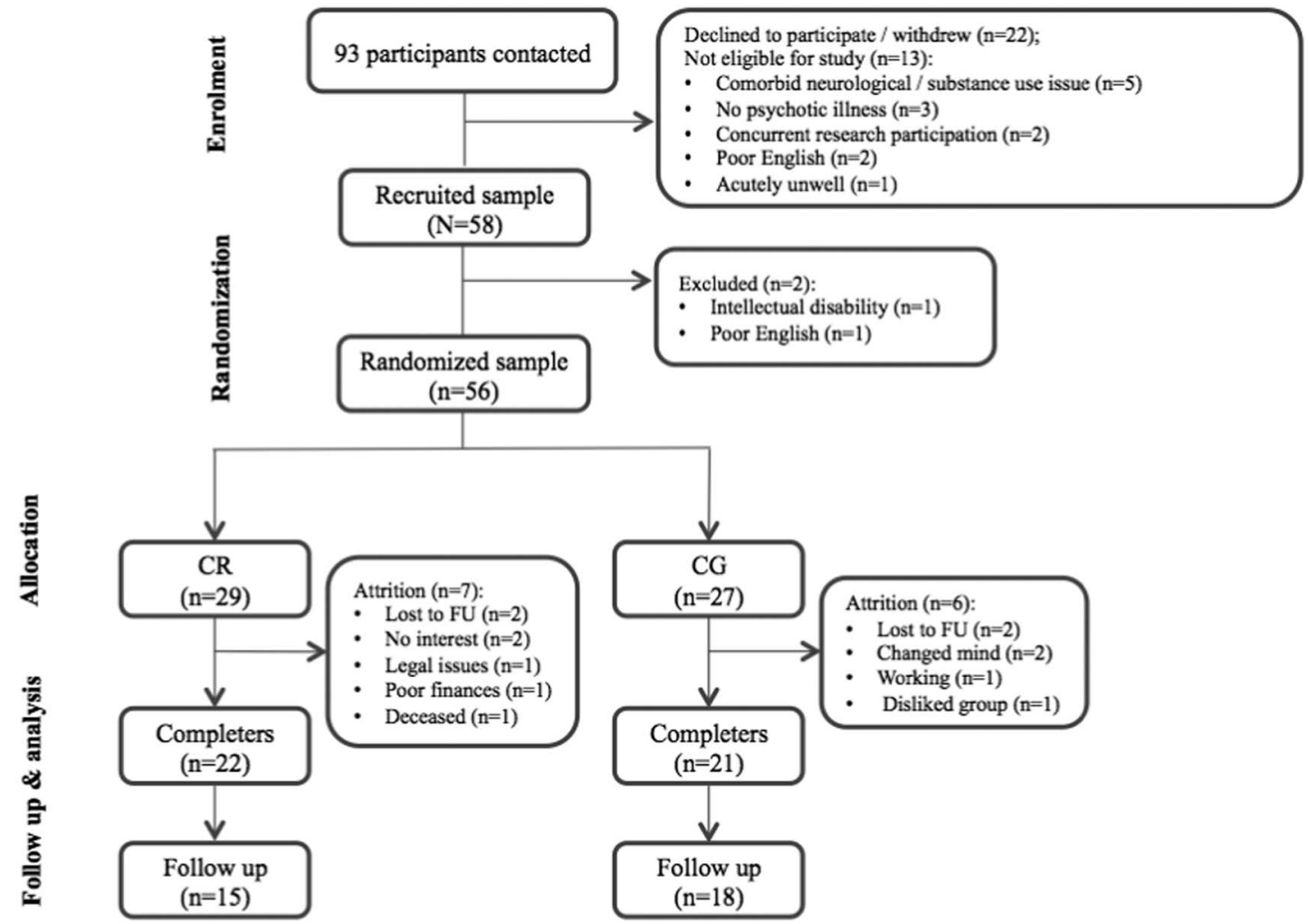

Fig. 1. CONSORT flow diagram illustrating participant progression through the trial. $\mathrm{CR}=$ cognitive remediation; $\mathrm{CG}=\mathrm{computer}$ games; $\mathrm{FU}=$ follow-up.

promoted as part of the group setting (Medalia \& Choi, 2010). A doctoral-level trainee ("provisional") psychologist (S.B.) facilitated all sessions and supported participant motivation, guided task selection, and maintained the training schedule. Participants attending at least $50 \%$ of sessions (i.e., $\geq 10 / 20$ ) were deemed group "completers".

\section{Cognitive remediation}

CR used COGPACK computer software (v.8.91, Marker Software ${ }^{\circledR}$ ). This package contains training exercises that target areas of cognitive impairment in schizophrenia including attention, new learning, and executive functions. CR trials using COGPACK have been found to improve cognitive test performance in people with schizophrenia, including interventions with only moderate training dosages (i.e., 10-36 hr over 4-12 weeks; Cavallaro et al., 2009; Lindenmayer et al., 2008; Sartory, Zorn, Groetzinger, \& Windgassen, 2005). Training followed a semi-structured protocol with two to three cognitive domains targeted per session. Sessions generally started with exercises targeting attention and reaction speed, and ended with those tapping higher-order constructs. Task difficulty was managed automatically or manually depending on the exercise. The COGPACK program provides feedback after every exercise on relevant parameters including "percentage correct" and "completion speed".

Drill-and-practice computer content was combined with additional instruction in internal cognitive strategies (e.g., semantic clustering, story method, imagery), which was led by the group facilitator. Strategy provision was partly informed by strategies described in the Thinking Skills for Work program (McGurk et al., 2005, 2016, 2015; McGurk \& Wykes, 2008) and in clinical CR guidelines (Wykes \& Reeder, 2005); yet focused specifically on improving training task performance without extension to everyday functioning.

Strategies were particularly targeted toward new learning and executive tasks. Participants first attempted tasks independently and received performance feedback from the computer program. This was then followed by in-session discussions about relevant task-specific strategies as well as encouragement to practice these or adopt new strategies in future learning trials. Learning content was contained within each 1-hr session. Similar models of CR using COGPACK have been implemented previously (Cavallaro et al., 2009; Contreras, Lee, Tan, Castle, \& Rossell, 2016).

\section{Computer games}

A CG playing group was used to control for non-specific training elements including routine, social interaction and computer stimulation. Computer activities chosen were commercially available games (e.g., arcade and puzzle games) with selection based on putative similarities to CR exercises including art style and interaction levels, and their use in other trials (Fisher et al., 2015). While CG playing participants had similar opportunities to socialize with the facilitator and other group members as those in CR, and instruction and task-specific advice was available when 
needed, there was no provision of internal cognitive strategies in this condition.

\section{Data Analysis}

Data were analyzed using SPSS software (v.21.0). Linear mixed-effect analyses were used to examine the impact of group, time and their interaction on the principal study outcomes. For each outcome, participants with completely missing data at every time point were removed from subsequent analyses. For cognition, three participants at baseline and one participant at end-group were missing at least one MCCB domain score, resulting in an incomplete calculation of a global cognition score. Since missingness was revealed to be random (Little's MCAR: $p>.05$ ), single imputation using expectation maximization was used to generate missing item scores estimated from all present MCCB items. This enabled computation of global cognition $t$-scores for these participants, which maximized the use of available observations. MCCB composites were not age and gendercorrected. This was due to our sample groups being matched for age and gender, the overall sample having a similar mean age as the U.S. normative sample, and lack of data showing whether the U.S. normative sample demographic stratification is consistent with the Australian population. This was thought to be a conservative approach to calculating $t$-scores.

The primary mixed-model analyses were conducted with intervention completers only. Models were run initially with fixed parameters and then reanalyzed with the inclusion of random intercepts. The repeated measurement covariance structure providing the best goodness-of-fit using Akaike Information Criterion with restricted maximum likelihood estimation was used to inform selection of the final model. Compound symmetry covariance structures provided the best fit for the global cognition and total symptom outcomes, while an unstructured configuration provided the best fit for the remaining measures. Bonferroni-adjusted pairwise comparisons were conducted to delineate significant interaction terms. Intention-to-treat (ITT) analyses using all randomized participants with at least one complete data point were used to examine the sensitivity of the completer-only models.

Reliable change indices were also calculated for individual and global MCCB cognitive domain(s) for participants providing complete baseline and end-group data $(\mathrm{CR}=22 ; \mathrm{CG}=20)$. One CG completer was removed from this investigation, having not attempted the end-group MCCB. Calculation of reliable change indices was used to determine those who demonstrated statistically meaningful improvement over time independent of measurement reliability. This analysis approach adopted methods proposed by Jacobson and Truax (1991) with MCCB test-retest reliability estimates and standard deviations obtained from Gray et al. (2014). A standardized cutoff of +1.65 (90\% confidence interval) was used to indicate reliable improvement. Cohen's $d$ effect sizes $\left(d_{z}\right)$ accounting for the correlation between MCCB domains at pre- and post-treatment were also estimated from this completer sample (Lakens, 2013).

\section{RESULTS}

\section{Impact of Group Interventions}

Results from the linear mixed-effect analyses using the completer-only sample are summarized in Table 2 . Significant time $(p<.001)$ and group $\times$ time interaction $(p=.028)$ effects were found for the primary outcome of global cognition, indicating greater benefit for the $\mathrm{CR}$ group. On secondary outcomes, a significant time main-effect was evident for everyday living and social self-efficacy $(p=.028)$ indicating both groups improved over time, but there was no significant group $\times$ time interaction. No significant effects were found for independent living skills, symptomatology, or quality of life.

Post hoc investigation of the interaction effect for global cognition was conducted using separate linear mixed-effect analyses, with time as the fixed effect for CR and CG groups separately. Bonferroni-adjusted pairwise comparisons were calculated, with an additional adjustment as two analyses were conducted independently for the two groups (significant difference concluded if the Bonferroni-adjusted pairwise comparison $p<.025$ ).

For CR participants, global cognition was significantly better than pre-group at both end of group $(p=.008)$ and 3 -month follow-up $(p<.001)$, whereas there was no significant difference in cognition between end-group and 3 -month follow-up $(p=.20)$. For CG participants, no significant pairwise differences were evident (all $p>.30$ ). For self-efficacy, the interaction term was not significant; however, on qualitative examination, the $\mathrm{CR}$ completers appeared to demonstrate a sustained improvement from end-group to 3-month follow-up, while CG participants trended toward pre-group levels after the end of group.

Re-analysis using the ITT sample was conducted to examine the sensitivity of the models when including all randomized participants. All mixed models remained significant, albeit with poorer goodness of fit, except for the general self-efficacy model, which became non-significant $(p=.096)$.

\section{Rates of Reliable Cognitive Improvement and Effect Size}

As shown in Table 3, five CR completers $(22.73 \%)$ demonstrated a statistically reliable improvement on global cognition from baseline to end-treatment in contrast with only two CG completers $(9.52 \%)$. Improvement on global cognition for $\mathrm{CR}$ completers corresponded with a moderate effect overall $\left(d_{z}=0.68\right)$ whereas only a very small effect for change was found for CG completers $\left(d_{z}=0.06\right)$. Seventeen CR (77.27\%) and nine CG (42.86\%) completers improved reliably in at least one MCCB cognitive domain.

\section{DISCUSSION}

This study examined the impact of a computer-assisted CR intervention, which had been supplemented with internal 
Table 2. Results of linear mixed-effect analyses on primary and secondary outcomes among CR and CG completers

\begin{tabular}{|c|c|c|c|c|c|c|c|}
\hline \multirow[b]{2}{*}{ Variable } & & Baseline & End-group & Three-months follow-up & Group x time & Group & Time \\
\hline & & $M(S E)$ & $M(S E)$ & $M(S E)$ & $p$ & $p$ & $p$ \\
\hline \multicolumn{8}{|l|}{ Primary outcome } \\
\hline \multirow[t]{3}{*}{ Global MCCB } & & & & & $.028 *$ & .79 & $<.001 *$ \\
\hline & $\mathrm{CR}$ & $30.82(2.38)$ & $34.55(2.38)$ & $37.07(2.46)$ & & & \\
\hline & $\mathrm{CG}$ & $32.52(2.43)$ & $32.90(2.45)$ & $34.38(2.47)$ & & & \\
\hline \multicolumn{8}{|c|}{ Secondary outcomes } \\
\hline \multirow[t]{3}{*}{ ILSS } & & & & & .69 & .43 & .11 \\
\hline & $\mathrm{CR}$ & $.711(.030)$ & $.727(.024)$ & $.730(.027)$ & & & \\
\hline & $\mathrm{CG}$ & $.723(.030)$ & $.755(.025)$ & $.771(.026)$ & & & \\
\hline \multirow[t]{3}{*}{ RSES } & & & & & .59 & .11 & $.028^{*}$ \\
\hline & $\mathrm{CR}$ & $98.14(4.60)$ & $109.77(5.06)$ & $110.02(4.86)$ & & & \\
\hline & $\mathrm{CG}$ & $110.95(4.71)$ & $119.18(5.23)$ & $116.15(4.74)$ & & & \\
\hline \multirow[t]{3}{*}{ EUROHIS-QOL } & & & & & .75 & .98 & .21 \\
\hline & $\mathrm{CR}$ & $26.96(1.05)$ & $28.32(1.08)$ & $27.27(1.20)$ & & & \\
\hline & $\mathrm{CG}$ & $26.57(1.08)$ & $28.00(1.10)$ & $27.85(1.16)$ & & & \\
\hline \multirow[t]{3}{*}{ PANSS } & & & & & .71 & .37 & .48 \\
\hline & $\mathrm{CR}$ & $61.82(3.20)$ & $60.96(3.20)$ & $60.93(3.57)$ & & & \\
\hline & $\mathrm{CG}$ & $60.29(3.28)$ & $57.66(3.33)$ & $55.35(3.45)$ & & & \\
\hline
\end{tabular}

Note. $N=43$.

$* p<.05$.

$\mathrm{CR}=$ Cognitive remediation; $\mathrm{CG}=$ computer games; EUROHIS-QOL = European Health Interview Survey - Quality of Life; ILSS-SR = Independent Living Skills Survey - Self-Report; MCCB = Matrics Consenus Cognitive Battery; M=mean; PANSS = Positive and Negative Syptom Scale; RSES=Revised Self-Efficacy Scale; $\mathrm{SE}=$ standard error.

cognitive strategies and delivered in a group setting, on global cognition, everyday self-efficacy and independent living skills in community-dwelling individuals with schizophrenia, when compared to an active CG playing control.

Consistent with our hypothesis, drill-and-strategy CR produced a moderate improvement in global cognition at end-treatment, which was also sustained at 3-month follow-up, with improvement greater than that achieved by an active control. This effect was observed to be relatively robust, occurring in both completer and ITT samples. In addition, three-quarters of CR completers demonstrated a statistically reliable change in at least one cognitive domain immediately following CR (c.f., $\leq 50 \%$ in CG), emphasizing that improvement was greater than that stemming from practice and/or non-specific effects experienced by $\mathrm{CG}$ completers.

Contrary to initial predictions, however, improvements in self-efficacy regarding everyday living and social abilities were comparable between CR and CG completers over time. This main effect became non-significant when all cases were estimated in the ITT sample, which may have been impacted by the complexity of non-completers who, relative to completers, had poorer cognition as well as higher levels of negative symptoms and self-efficacy. Consequently, these participants may have had less capacity for change. There was no change in self-reported independent living skills, overall symptoms, or quality of life following intervention completion.

\section{Comparisons With Previous Research and Implications}

\section{Cognition}

Overall, these findings are broadly consistent with conclusions from the most comprehensive meta-analysis, that $\mathrm{CR}$ can produce moderate improvements in cognitive test performance relative to control conditions at post-treatment $(d=0.45)$, which may also be durable $(d=0.43)$ at least over the short term (Wykes et al., 2011). The findings also provide support for drill-andstrategy CR using COGPACK as capable of improving cognitive test performance, which in this study, was evident among completers even despite an average attendance of 13 sessions.

A decision was made to deliver an intervention that was considered feasible in a community context (Medalia \& Richardson, 2005; Wauchope, Terlich, \& Lee, 2016); however, most previous RCTs describing cognitive benefits using this program have offered 24- to 36-hr schedules of outpatient training over 3-6 months (Cavallaro et al., 2009; Lindenmayer et al., 2008; McGurk et al., 2005; Vita et al., 2011). Global cognitive effect sizes may be larger following intense, restoratively based training programs $(d=0.86)$ providing $50-100 \mathrm{hr}$ over 10-20 weeks (Fisher et al., 2009, 2010; Subramaniam et al., 2012). However, direct systematic comparisons of specific training approaches (i.e., drill-and-practice $v s$. drill-and-strategy) on training usage and outcomes are lacking.

In terms of sample characteristics, baseline cognitive ability among completers was considered fairly representative of other schizophrenia samples, with most cognitive domains 
Table 3. Comparison of reliable improvements and effect sizes in MCCB domains between CR and CG completers

\begin{tabular}{|c|c|c|c|c|c|c|}
\hline \multirow[b]{2}{*}{ MCCB domain } & & Baseline & End-group & \multicolumn{2}{|c|}{ Reliably improved } & \multirow[b]{2}{*}{$d_{z}$} \\
\hline & & \multicolumn{2}{|c|}{$M(S D)$} & $n$ & $\%$ & \\
\hline \multicolumn{7}{|l|}{ Processing speed } \\
\hline & $\mathrm{CR}$ & $37.45(10.01)$ & 40.68 (11.19) & 2 & 9 & 0.51 \\
\hline & $\mathrm{CG}$ & $40.45(9.31)$ & $40.55(9.68)$ & 0 & 0 & 0.02 \\
\hline \multicolumn{7}{|l|}{ Attention } \\
\hline & $\mathrm{CR}$ & $35.55(12.21)$ & $41.23(10.44)$ & 7 & 32 & 0.49 \\
\hline & $\mathrm{CG}$ & 40.95 (13.02) & $40.45(12.70)$ & 2 & 10 & 0.05 \\
\hline \multicolumn{7}{|c|}{ Working memory } \\
\hline & $\mathrm{CR}$ & $39.18(11.33)$ & $42.91(11.16)$ & 2 & 9 & 0.63 \\
\hline & $\mathrm{CG}$ & $37.70(9.10)$ & $39.80(10.22)$ & 1 & 5 & 0.31 \\
\hline \multicolumn{7}{|l|}{ Verbal learning } \\
\hline & $\mathrm{CR}$ & $35.36(8.43)$ & $35.55(9.37)$ & 2 & 9 & 0.02 \\
\hline & $\mathrm{CG}$ & $40.15(9.02)$ & $35.05(7.86)$ & 0 & 0 & 0.54 \\
\hline \multicolumn{7}{|l|}{ Visual learning } \\
\hline & $\mathrm{CR}$ & $36.27(14.51)$ & $43.14(13.46)$ & 8 & 36 & 1.00 \\
\hline & $\mathrm{CG}$ & $33.40(12.21)$ & $37.85(10.92)$ & 7 & 35 & 0.60 \\
\hline \multicolumn{7}{|c|}{ Reasoning and problem solving } \\
\hline & $\mathrm{CR}$ & $43.55(10.20)$ & $39.36(6.25)$ & 0 & 0 & 0.58 \\
\hline & CG & $40.15(5.88)$ & $40.05(8.10)$ & 0 & 0 & 0.02 \\
\hline \multicolumn{7}{|l|}{ Social cognition } \\
\hline & $\mathrm{CR}$ & $39.09(12.78)$ & $41.36(14.07)$ & 2 & 9 & 0.28 \\
\hline & CG & $43.95(11.01)$ & $44.75(12.79)$ & 1 & 5 & 0.10 \\
\hline \multicolumn{7}{|l|}{ Global composite } \\
\hline & $\mathrm{CR}$ & $30.82(11.65)$ & $34.55(11.88)$ & 5 & 23 & 0.68 \\
\hline & $\mathrm{CG}$ & $33.25(10.45)$ & $33.55(10.12)$ & 2 & 10 & 0.06 \\
\hline \multicolumn{7}{|c|}{ Improved in at least one domain } \\
\hline & $\mathrm{CR}$ & - & - & 17 & 77 & - \\
\hline & CG & - & - & 9 & 45 & - \\
\hline
\end{tabular}

Note. Reliable improvement based on a reliable change index of +1.65 (i.e. $90 \%$ confidence level).

Percentage improved reported to the nearest whole number.

Reliable change index and Cohen's d effect size estimated using the per-protocol completer sample (i.e. $C R=22 ; C G=20$ ).

$\mathrm{CR}=$ Cognitive remediation; $\mathrm{CG}=$ computer games; $d_{z}=$ Cohen's $\mathrm{d} ; \mathrm{MCCB}=$ Matrics Consenus Cognitive Battery; $M=$ mean;

$S D=$ standard deviation

falling within reported ranges of 1-2 SDs below healthy controls (Heinrichs \& Zakzanis, 1998). There was also consistency in global cognition levels between study completers $(M=31.65 ; S D=11.01)$ and those in multi-site cognitive evaluations as well as other clinical trials in people with schizophrenia $(M=26.7-35.31) \quad$ (August, Kiwanuka, McMahon, \& Gold, 2012; Keefe et al., 2011; Lindenmayer et al., 2013).

PANSS total symptom ratings revealed that participants were, on average, at the upper end of "mildly ill" (i.e., 61.07) at the time of recruitment (Leucht, 2014); well within ranges reported in previous schizophrenia studies using COGPACK (Bosia et al., 2017; Lindenmayer et al., 2013; Scheu et al., 2013; Vita et al., 2011). Accordingly, the CR intervention described here may be suitable for communitydwelling individuals with schizophrenia experiencing typical levels of cognitive impairment and moderate symptomatology.

Further consideration appears warranted, however, regarding factors contributing to the observed cognitive benefits for CR completers, particularly given the emphasis on task-specific instructional strategies in a relatively chronic middle-aged sample. Experiential evidence has previously highlighted the importance of instructional methods to perceived cognitive and everyday improvements in people with schizophrenia completing CR (Contreras et al., 2016). In the current study, participants were encouraged to try strategies designed to improve cognitive test performance during exercises, with the expectation that techniques viewed as useful would be adopted in future learning trials and task performances become more efficient over time. In this regard, CR offered an opportunity to learn strategies that could assist participants in overcoming task-specific cognitive challenge. This model is distinct from "drill-and-practice" approaches that purport to bring about cognitive improvement via putative restorative benefits that occur during repeated practice (Vinogradov, Fisher, \& de Villers-Sidani, 2012).

Previous studies have suggested that shorter group-based, drill-and-practice training (e.g., $10 \mathrm{hr}$ over 3-4 weeks) may be more likely to produce cognitive change in less chronic samples (Rauchensteiner et al., 2011; Sartory et al., 2005). Lower intensity restorative interventions may not be sufficient 
for individuals with a prolonged illness course due to factors including lower potential for neuroplastic training responses, longer-term exposure to antipsychotic medications and greater disease burden (Fisher, Subramaniam, Panizzutti, \& Vinogradov, 2013; Rauchensteiner et al., 2011; Vinogradov et al., 2009).

The fact that CR completers in this study improved their cognitive performance following a relatively short drill-and-strategy intervention raises the possibility that strategic instruction may promote near-transfer effects on cognitive tests in more chronic participants (Fiszdon et al., 2006). As there was no comparison with a drill-andpractice training model in this study, however, we cannot be sure what aspects of the training underpinned the gains made.

Clinically, it is important to note that effective utilization of strategy-based methods may be dependent on multiple cognitive factors including functional learning and memory skills and metacognitive awareness to recognize scenarios where strategies should be applied (Farreny et al., 2016; Velikonja et al., 2014; Wykes \& Reeder, 2005). Exacerbation of acute affective and/or psychotic symptoms may further complicate the learning process, as may motivational factors. Consideration of participant characteristics may be important when identifying the most appropriate cognitively enhancing intervention.

Individuals with pronounced dysexecutive symptoms, including apathy or disinhibition for example, might respond better to structured external compensatory interventions that focus more directly on real-world activities such as Cognitive Adaptation Training (Allott, Killackey, Sun, Brewer, \& Velligan, 2016; Draper, Stutes, Maples, \& Velligan, 2009; Maples \& Velligan, 2008). CAT aims to maximize cognitive strengths and support adaptive everyday behaviors by optimizing external strategies and environmental adaptations, while circumnavigating areas of cognitive impairment (Maples \& Velligan, 2008). There is a significant need for research examining patient characteristics that influence treatment as well as comparisons of CR interventions with functionally grounded approaches.

The role of specific therapeutic characteristics on trainingrelated gains may also require further consideration. It is unclear whether increasing the length and/or intensity of the current intervention would have produced greater cognitive benefits. However, Wykes et al. (2011) demonstrated that therapeutic parameters, such as treatment duration, may not moderate the cognitive effect sizes in CR. Additionally, although few studies have directly manipulated training exposure, a recent study comparing cognitive outcomes at 3 and 6 months of COGPACK training revealed no further cognitive improvement with the additional 3 months of training (Buonocore et al., 2017). Cognitive effects of CR may, therefore, plateau once a sufficient treatment threshold has been reached (Buonocore et al., 2017). Nevertheless, it cannot be determined whether participants obtained optimal training exposure for the current intervention. Identifying specific training parameters that may modify treatment outcomes, whether their impact differs according to intervention approach, and how these interact with patient characteristics (i.e., motivation), represent important areas of future investigation (McGurk et al., 2013).

\section{Independent Living Skills}

There was no effect of drill-and-strategy CR on self-reported living skills despite internal strategy provision and evidence of increased cognition and everyday efficacy in this trial. This is also despite everyday living skills being arguably more proximal to the $\mathrm{CR}$ training exercises compared to other functional outcomes (e.g., occupational status) as well as their close association with cognitive impairment in schizophrenia (Harvey et al., 2012; Kurtz, 2012). This study is, therefore, consistent with others that have failed to demonstrate generalization of gains from cognitive training to the real world in individuals with schizophrenia (Dickinson et al., 2010; Fisher et al., 2009; Gomar et al., 2015; Murthy et al., 2012) and other patient groups (das Nair, Martin, \& Lincoln, 2016; van Heugten, Ponds, \& Kessels, 2016).

Studies providing the strongest evidence for functional generalization using CR in schizophrenia have combined remediation with access to parallel intervention(s) including vocational or social cognitive training; personalized goal setting; functionally relevant strategies; and/or explicit bridging sessions to link training exercise and techniques with everyday activities (Bowie et al., 2012; Lindenmayer et al., 2013; Wykes et al., 2011). These elements were not included in the present study. This may suggest that psychosocial disability may need to be addressed directly if the primary intervention goal is improved community functioning (Mueser, 2012).

An additional point of consideration, however, is that this intervention may not have been of sufficient "dose" to support improvement in everyday functioning. On average, participants only attended 13 sessions; well below commonly idealized intervention schedules in schizophrenia samples (e.g., two to three sessions/week for 3-6 months; Medalia \& Richardson, 2005; Mueser, Deavers, Penn, \& Cassisi, 2013). Previous studies have described functional benefits in the context of longer 24-36 hr CR intervention schedules using COGPACK (Cavallaro et al., 2009; Lindenmayer et al., 2008; Vita et al., 2011), although the unique real world benefits of CR using this program alone are difficult to interpret given that it is often combined with functional interventions (McGurk et al., 2005, 2015).

The 3-month follow-up used in this study may also have been too short to detect changes in independent living skills. Cognitive enhancement among CR participants has been associated with greater quality of life and social functioning at 6-months post-treatment (Fisher et al., 2010; Wykes et al., 2007). Research exploring the impact of CR on functional outcomes when delivered as a single-modal intervention and predictors of improved community engagement is, therefore, required. 


\section{Self-efficacy}

One unique study finding was that both CR and CG completers reported improvements in self-efficacy concerning their ability to successfully complete everyday living and social tasks. While few previous studies have explored whether CR can enhance everyday confidence beliefs beyond controls or whether this generalizes to broader functioning, others have investigated training-specific expectations of success (i.e., perceived competency), revealing these to be responsive to cognitive interventions and predictive of training-related improvements (Bowie et al., 2017; Choi \& Medalia, 2010; Saperstein \& Kurtz, 2013). Non-psychiatric models posit that self-efficacy can be enhanced through multiple pathways including the reinforcement of success during challenging tasks and perceived mastery, vicarious learning via observed peer achievements, and through verbal persuasion and titrated social support (Bandura, 1977). These processes may have been present in both stimulating group-based interventions in this trial.

The current study findings suggest that sustained participation in both cognitively and socially engaging programs facilitated improvements in confidence in broader functional domains, thus representing a group-related intrinsic "side-effect". Group completers may, for example, have felt more confident in their ability to undertake activities that were part of the intervention, such as to "talk to people in a group," "concentrate on your work," and "get out of the house". Nevertheless, some caution is warranted when considering the potential therapeutic benefit of these interventions in self-efficacy in the absence of a non-intervention control. Self-efficacy may have increased spontaneously in the context of treatment-as-usual.

In addition, the stability of observed enhancements in self-efficacy over the longer term remains unclear. Qualitatively, estimated marginal means suggested that, although everyday self-efficacy was higher at all time points in the CG playing condition, reported levels appeared to trend downward from end-group to follow-up in the control. This pattern was not observed in the CR group, which may suggest that the two interventions impacted on self-efficacy differently over time. Exploring the extent to which cognitively stimulating interventions can impact underlying everyday confidence beliefs, their progression over time, and their relationship with real-world functioning appears necessary.

\section{Limitations}

The following limitations must be considered when interpreting these findings. While this study aimed to gain a better understanding of community-based CR alone, the intervention did not include a direct focus on real-world generalization. This appears to have reduced potential for change in independent living skills. Without longer follow-up it is also unclear how cognitive and self-efficacy improvements progressed over time. The sample size was modest, although appeared sufficient to power the primary mixed-model analysis. In addition, while the integration of strategies into training falls within contemporary definitions of $\mathrm{CR}$, the current design cannot disentangle whether computer content or strategy use, or their interaction, was responsible for the observed cognitive improvement. A single facilitator ran all of $\mathrm{CR}$ and CG playing groups; however, any potential bias in empathy and motivational capacity was likely systematically applied across conditions.

Furthermore, the statistical trend favoring higher selfefficacy in the control group at baseline may have masked a possible group $\times$ time interaction effect. Finally, the use of a self-report scale of living skills was potentially problematic given that completion is reliant on functional memory and introspection. Capacity-based functional measures (e.g., UCSD Performance-Based Skills Assessment), which are more strongly correlated with cognition, may be more sensitive to potential far-transfer (Elliott \& Fiszdon, 2014; Harvey, Velligan, \& Bellack, 2007). In retrospect, the ILSS-SR may have been more suitable in an intervention targeting psychiatric symptoms given recently reported relationships between the ILSS-SR and emotional distress (Elliott \& Fiszdon, 2014).

Taken together, the current study provides additional evidence that $\mathrm{CR}$ delivered over 20 sessions in the community, even with a mean attendance of 13 , may produce changes in cognitive test performance in people living with schizophrenia. Additionally, this trial suggests that stimulating group programs may produce improvements in self-efficacy regarding everyday living and social behaviors, presumably via non-specific elements including social engagement, positive learning experiences, and commitment to a stimulating community-based program. However, meaningful gains in real-world functional domains such as everyday living skills, an overarching goal of many cognitive enhancement programs, may be unlikely to occur when using this type of intervention.

Methods of achieving improved community function require further investigation. Rehabilitation approaches that focus directly on real-world tasks in an individualized manner, which may include various extents of functional compensation, are likely needed to capitalize on gains in cognitive skills and achieve a lasting reduction in psychosocial disability. There is a pressing need to examine the efficacy of such interventions to improve quality of life and optimize functional engagement for individuals with schizophrenia.

\section{REGISTRATION DETAILS}

The trial was registered retrospectively with Australian and New Zealand Clinical Trial Registry (ANZCTR, http://www. anzctr.org.au/) on 24/10/16 (trial number: ACTRN 12616001476426).

\section{ACKNOWLEDGEMENTS}

The authors declare no conflicts of interest. The conduct of this research was supported by doctoral and honors funds provided by the School of Psychological Sciences at Monash University as well 
as an equipment grant provided by Faculty of Health, Arts and Design at Swinburne University. Shayden Bryce and Richard Lawrence are in receipt of a Research Training Program stipend funded by Monash University. Sean Carruthers is in receipt of a Research Training Program stipend funded by Swinburne University. Stuart Lee is in receipt of a National Health and Medical Research Council Early Career Fellowship. We thank all of the people that supported the conduct of this study and invested their time and effort into making it possible. We are particularly indebted to our participants and hope their experiences were beneficial in their journey toward recovery.

\section{SUPPLEMENTARY MATERIAL}

To view supplementary material for this article, please visit https://doi.org/10.1017/S1355617717001369

\section{REFERENCES}

Allott, K.A., Killackey, E., Sun, P., Brewer, W.J., \& Velligan, D.I. (2016). Feasibility and acceptability of cognitive adaptation training for first-episode psychosis. Early Intervention in Psychiatry, 10(6), 476-484. doi: 10.1111/eip.12207

American Psychiatric Association. (2000). Diagnostic and statistical manual of mental disorders (4th ed, text rev.). Washington, DC: Author.

August, S.M., Kiwanuka, J.N., McMahon, R.P., \& Gold, J.M. (2012). The MATRICS Consensus Cognitive Battery (MCCB): Clinical and cognitive correlates. Schizophrenia Research, 134 (1), 76-82. doi: 10.1016/j.schres.2011.10.015

Bandura, A. (1977). Self-efficacy: Toward a unifying theory of behavioral change. Psychological Review, 84(2), 191-215. doi: 10.1037/0033-295X.84.2.191

Bosia, M., Buonocore, M., Bechi, M., Spangaro, M., Pigoni, A., Croci, M., ... Cavallaro, R. (2017). Cognitive remediation and functional improvement in schizophrenia: Is it a matter of size? European Psychiatry, 40, 26-32. doi: 10.1016/j. eurpsy.2016.06.007

Bowie, C.R., Grossman, M., Gupta, M., Holshausen, K., \& Best, M.W. (2017). Action-based cognitive remediation for individuals with serious mental illnesses: Effects of real-world simulations and goal setting on functional and vocational outcomes. Psychiatric Rehabilitation Journal, 40(1), 53-60. doi: 10.1037/prj0000189

Bowie, C.R., Leung, W.W., Reichenberg, A., McClure, M.M., Patterson, T.L., Heaton, R.K., \& Harvey, P.D. (2008). Predicting schizophrenia patients' real-world behavior with specific neuropsychological and functional capacity measures. Biological Psychiatry, 63(5), 505-511. doi: 10.1016/j.biopsych.2007.05.022

Bowie, C.R., McGurk, S.R., Mausbach, B.T., Patterson, T.L., \& Harvey, P.D. (2012). Combined cognitive remediation and functional skills training for schizophrenia: Effects on cognition, functional competence, and real-world behavior. American Journal of Psychiatry, 169, 710-718.

Bowie, C.R., Reichenberg, A., Patterson, T.L., Heaton, R.K., \& Harvey, P.D. (2006). Determinants of real-world functional performance in schizophrenia subjects: Correlations with cognition, functional capacity, and symptoms. American Journal of Psychiatry, 163(3), 418-425.

Bryce, S., Sloan, E., Lee, S., Ponsford, J., \& Rossell, S. (2016). Cognitive remediation in schizophrenia: A methodological appraisal of systematic reviews and meta-analyses. Journal of Psychiatric Research, 75, 91-106. doi: 10.1016/j.jpsychires.2016.01.004

Buonocore, M., Bosia, M., Bechi, M., Spangaro, M., Cavedoni, S., Cocchi, F., ... Cavallaro, R. (2017). Is longer treatment better? A comparison study of 3 versus 6 months cognitive remediation in schizophrenia. Neuropsychology, 31(4), 467-473. doi: 10.1037/ neu0000347

Cardenas, V., Abel, S., Bowie, C.R., Tiznado, D., Depp, C.A., Patterson, T.L., ... Mausbach, B.T. (2013). When functional capacity and real-world functioning converge: The role of self-efficacy. Schizophrenia Bulletin, 39(4), 908-916. doi: 10.1093/ schbul/sbs004

Cavallaro, R., Anselmetti, S., Poletti, S., Bechi, M., Ermoli, E., Cocchi, F., ... Smeraldi, E. (2009). Computer-aided neurocognitive remediation as an enhancing strategy for schizophrenia rehabilitation. Psychiatry Research, 169(3), 191-196. doi: 10.1016/j.psychres.2008.06.027

Choi, J., \& Medalia, A. (2010). Intrinsic motivation and learning in a schizophrenia spectrum sample. Schizophrenia Research, 118 (1-3), 12-19. doi: 10.1016/j.schres.2009.08.001

Contreras, N.A., Lee, S., Tan, E.J., Castle, D.J., \& Rossell, S.L. (2016). "How is cognitive remediation training perceived by people with schizophrenia? A qualitative study examining personal experiences". Journal of Mental Health (Abingdon, England), 25(3), 260-266. doi: 10.3109/09638237.2016.1167856

d'Amato, T., Bation, R., Cochet, A., Jalenques, I., Galland, F., Giraud-Baro, E., ... Brunelin, J. (2011). A randomized, controlled trial of computer-assisted cognitive remediation for schizophrenia. Schizophrenia Research, 125(2-3), 284-290. doi: 10.1016/j.schres.2010.10.023

das Nair, R., Martin, K.J., \& Lincoln, N.B. (2016). Memory rehabilitation for people with multiple sclerosis. Cochrane Database of Systematic Reviews, 2016(3) doi: 10.1002/14651858. CD008754.pub3

Dickinson, D., Tenhula, W., Morris, S., Brown, C., Peer, J., Spencer, K., ... Bellack, A.S. (2010). A randomized, controlled trial of computer-assisted cognitive remediation for schizophrenia. American Journal of Psychiatry, 167(2), 170-180.

Dixon, L.B., Dickerson, F., Bellack, A.S., Bennett, M., Dickinson, D., Goldberg, R.W., ... Kreyenbuhl, J. (2010). The 2009 schizophrenia PORT psychosocial treatment recommendations and summary statements. Schizophrenia Bulletin, 36(1), 48-70.

Draper, M.L., Stutes, D.S., Maples, N.J., \& Velligan, D.I. (2009). Cognitive adaptation training for outpatients with schizophrenia. Journal of Clinical Psychology, 65(8), 842-853. doi: 10.1002/ jclp. 20612

Elliott, C.S., \& Fiszdon, J.M. (2014). Comparison of self-report and performance-based measures of everyday functioning in individuals with schizophrenia: Implications for measure selection. Cognitive Neuropsychiatry, 1-10. doi: 10.1080/ 13546805.2014.922062

Farreny, A., Aguado, J., Corbera, S., Ochoa, S., Huerta-Ramos, E., \& Usall, J. (2016). Baseline predictors for success following strategy-based cognitive remediation group training in schizophrenia. The Journal of Nervous and Mental Disease, 204(8), 585-589. doi: 10.1097/NMD.0000000000000509

Fett, A.K., Viechtbauer, W., Dominguez, M.D., Penn, D.L., van Os, J., \& Krabbendam, L. (2011). The relationship between neurocognition and social cognition with functional outcomes in schizophrenia: A meta-analysis. Neuroscience and Biobehavioral Reviews, 35(3), 573-588. doi: 10.1016/j. neubiorev.2010.07.001 
Fisher, M., Holland, C., Merzenich, M.M., \& Vinogradov, S. (2009). Using neuroplasticity-based auditory training to improve verbal memory in schizophrenia. American Journal of Psychiatry, 166(7), 805-811.

Fisher, M., Holland, C., Subramaniam, K., \& Vinogradov, S. (2010). Neuroplasticity-based cognitive training in schizophrenia: An interim report on the effects 6 months later. Schizophrenia Bulletin, 36(4), 869-879. doi: 10.1093/schbul/sbn170

Fisher, M., Loewy, R., Carter, C., Lee, A., Ragland, J.D., Niendam, T., ... Vinogradov, S. (2015). Neuroplasticity-based auditory training via laptop computer improves cognition in young individuals with recent onset schizophrenia. Schizophrenia Bulletin, 41(1), 250-258. doi: $10.1093 /$ schbul/sbt232

Fisher, M., Subramaniam, K., Panizzutti, R., \& Vinogradov, S. (2013). Computerized cognitive training in schizophrenia: Current knowledge and future directions. In P.D. Harvey (Ed.), Cognitive impairment in schizophrenia: Characteristics, assessment and treatment (pp. 284-315). New York, NY: Cambridge University Press.

Fiszdon, J.M., McClough, J.F., Silverstein, S.M., Bell, M.D., Jaramillo, J.R., \& Smith, T.E. (2006). Learning potential as a predictor of readiness for psychosocial rehabilitation in schizophrenia. Psychiatry Research, 143(2-3), 159-166. doi: 10.1016/j.psychres.2005.09.012

Galletly, C., Castle, D., Dark, F., Humberstone, V., Jablensky, A., Killackey, E., ... Tran, N. (2016). Royal Australian and New Zealand College of Psychiatrists clinical practice guidelines for the management of schizophrenia and related disorders. Australian and New Zealand Journal of Psychiatry, 50(5), 410-472. doi: 10.1177/0004867416641195

Gomar, J.J., Valls, E., Radua, J., Mareca, C., Tristany, J., del Olmo, F., ... McKenna, P.J. (2015). A multisite, randomized controlled clinical trial of computerized cognitive remediation therapy for schizophrenia. Schizophrenia Bulletin, 41(6), 1387-1396. doi: 10.1093/schbul/sbv059

Gray, B.E., McMahon, R.P., Green, M.F., Seidman, L.J., Mesholam-Gately, R.I., Kern, R.S., ... Gold, J.M. (2014). Detecting reliable cognitive change in individual patients with the MATRICS Consensus Cognitive Battery. Schizophrenia Research, 159(1), 182-187. doi: 10.1016/j.schres.2014.07.032

Green, M.F., Kern, R.S., \& Heaton, R.K. (2004). Longitudinal studies of cognition and functional outcome in schizophrenia: Implications for MATRICS. Schizophrenia Research, 72(1), 41-51. doi: 10.1016/j.schres.2004.09.009

Grynszpan, O., Perbal, S., Pelissolo, A., Fossati, P., Jouvent, R., Dubal, S., ... Perez-Diaz, F. (2011). Efficacy and specificity of computer-assisted cognitive remediation in schizophrenia: A meta-analytical study. Psychological Medicine, 41(1), 163-173. doi: 10.1017/S0033291710000607

Hargreaves, A., Dillon, R., Anderson-Schmidt, H., Corvin, A., Fitzmaurice, B., Castorina, M., ... Donohoe, G. (2015). Computerised working-memory focused cognitive remediation therapy for psychosis-A preliminary study. Schizophrenia Research, 169(1-3), 135-140. doi: 10.1016/j.schres.2015. 09.004

Harvey, P., \& Strassnig, M. (2012). Predicting the severity of everyday functional disability in people with schizophrenia: Cognitive deficits, functional capacity, symptoms, and health status. World Psychiatry, 11, 73-79.

Harvey, P.D., Heaton, R.K., Carpenter, W.T. Jr., Green, M.F., Gold, J.M., \& Schoenbaum, M. (2012). Functional impairment in people with schizophrenia: Focus on employability and eligibility for disability compensation. Schizophrenia Research, 140(1-3), 1-8. doi: 10.1016/j.schres.2012.03.025

Harvey, P.D., Velligan, D.I., \& Bellack, A.S. (2007). Performancebased measures of functional skills: Usefulness in clinical treatment studies. Schizophrenia Bulletin, 33(5), 1138-1148. doi: 10.1093/schbul/sbm040

Heinrichs, R.W., \& Zakzanis, K.K. (1998). Neurocognitive deficit in schizophrenia: A quantitative review of the evidence. Neuropsychology, 12(3), 426-445.

Jacobson, N.S., \& Truax, P. (1991). Clinical significance: A statistical approach to defining meaningful change in psychotherapy eesearch. Journal of Consulting and Clinical Psychology, 59(1), 12-19.

Kay, S.R., Fiszbein, A., \& Opler, L.A. (1987). The positive and negative syndrome scale (PANSS) for schizophrenia. Schizophrenia Bulletin, 13(2), 261-276.

Keefe, R.S., Fox, K.H., Harvey, P.D., Cucchiaro, J., Siu, C., \& Loebel, A. (2011). Characteristics of the MATRICS Consensus Cognitive Battery in a 29-site antipsychotic schizophrenia clinical trial. Schizophrenia Research, 125(2-3), 161-168. doi: 10.1016/j.schres.2010.09.015

Kern, R.S., Glynn, S.M., Horan, W.P., \& Marder, S.R. (2009). Psychosocial treatments to promote functional recovery in schizophrenia. Schizophrenia Bulletin, 35(2), 347-361. doi: 10.1093/schbul/sbn 177

Kern, R.S., Nuechterlein, K.H., Green, M.F., Baade, L.E., Fenton, W.S., Gold, J.M., ... Marder, S.R. (2008). The MATRICS Consensus Cognitive Battery, part 2: Co-norming and standardization. American Journal of Psychiatry, 165(2), 214-220. doi: 10.1176/appi.ajp.2007.07010043

Kurtz, M.M. (2012). Cognitive remediation for schizophrenia: Current status, biological correlates and predictors of response. Expert Review of Neurotherapeutics, 12(7), 813-821.

Kurtz, M.M., Seltzer, J.C., Shagan, D.S., Thime, W.R., \& Wexler, B.E. (2007). Computer-assisted cognitive remediation in schizophrenia: What is the active ingredient? Schizophrenia Research, 89(1-3), 251-260. doi: 10.1016/j.schres.2006.09.001

Lakens, D. (2013). Calculating and reporting effect sizes to facilitate cumulative science: A practical primer for t-tests and ANOVAs. Frontiers in Psychology, 4, 863. doi: 10.3389/fpsyg.2013.00863

Leifker, F.R., Patterson, T.L., Heaton, R.K., \& Harvey, P.D. (2011). Validating measures of real-world outcome: The results of the VALERO expert survey and RAND panel. Schizophrenia Bulletin, 37(2), 334-343. doi: 10.1093/schbul/sbp044

Leucht, S. (2014). Measurements of response, remission, and recovery in schizophrenia and examples for their clinical application. The Journal of Clinical Psychiatry, 75(Suppl 1), 8-14. doi: 10.4088/JCP.13049su1c.02

Lindenmayer, J.P., McGurk, S.R., Khan, A., Kaushik, S., Thanju, A., Hoffman, L., ... Herrmann, E. (2013). Improving social cognition in schizophrenia: A pilot intervention combining computerized social cognition training with cognitive remediation. Schizophrenia Bulletin, 39(3), 507-517. doi: 10.1093/schbul/sbs120

Lindenmayer, J.P., McGurk, S.R., Mueser, K.T., Khan, A., Wance, D., Hoffman, L., ... Xie, H. (2008). A randomized controlled trial of cognitive remediation among inpatients with persistent mental illness. Psychiatric Services, 59, 241-247.

Maples, N.J., \& Velligan, D.I. (2008). Cognitive adaptation training: Establishing environmental supports to bypass cognitive deficits and improve functional outcomes. American Journal of Psychiatric Rehabilitation, 11(2), 164-180. doi: 10.1080/15487760801963686 
McDermott, B.E. (1995). Development of an instrument for assessing self-efficacy in schizophrenic spectrum disorders. Journal of Clinical Psychology, 51, 320-331.

McGurk, S.R., Mueser, K.T., Covell, N.H., Cicerone, K.D., Drake, R.E., Silverstein, S.M., ... Essock, S.M. (2013). Mental health system funding of cognitive enhancement interventions for schizophrenia: Summary and update of the New York Office of Mental Health expert panel and stakeholder meeting. Psychiatric Rehabilitation Journal, 36(3), 133-145. doi: $10.1037 / \mathrm{prj0000020}$

McGurk, S.R., Mueser, K.T., \& Pascaris, A. (2005). Cognitive training and supported employment for persons with severe mental illness: One-year results from a randomized controlled trial. Schizophrenia Bulletin, 31(4), 898-909. doi: 10.1093/schbul/sbi037

McGurk, S.R., Mueser, K.T., Xie, H., Feldman, K., Shaya, Y., Klein, L., ... Wolfe, R. (2016). Cognitive remediation for vocational rehabilitation nonresponders. Schizophrenia Research, 175(1-3), 48-56. doi: 10.1016/j.schres.2016.04.045

McGurk, S.R., Mueser, K.T., Xie, H., Welsh, J., Kaiser, S., Drake, R.E., ... McHugo, G.J. (2015). Cognitive enhancement treatment for people with mental illness who do not respond to supported employment: A randomized controlled trial. American Journal of Psychiatry, 172(9), 852-861. doi: 10.1176/appi.ajp. 2015.14030374

McGurk, S.R., Twamley, E.W., Sitzer, D.I., McHugo, G.J., \& Mueser, K.T. (2007). A meta-analysis of cognitive remediation in schizophrenia. American Journal of Psychiatry, 164(12), 1791-1802.

McGurk, S.R., \& Wykes, T. (2008). Cognitive remediation and vocational rehabilitation. Psychiatric Rehabilitation Journal, 31 (4), 350-359. doi: 10.2975/31.4.2008.350.359

Medalia, A., \& Choi, J. (2010). Motivational enhancements in schizophrenia. In V. Roder \& A. Medalia (Eds.), Neurocognition and social cognition in schizophrenia patients: Basic Concepts and Treatment (pp. 158-172). Basel, Switzerland: Karger.

Medalia, A., \& Richardson, R. (2005). What predicts a good response to cognitive remediation interventions? Schizophrenia Bulletin, 31(4), 942-953. doi: 10.1093/schbul/sbi045

Mueser, K.T. (2012). Should psychosocial treatment for schizophrenia focus on the proximal or distal consequences of the disorder? Journal of Mental Health (Abingdon, England), 21(6), 525-530. doi: 10.3109/09638237.2012.745192

Mueser, K.T., Deavers, F., Penn, D.L., \& Cassisi, J.E. (2013). Psychosocial treatments for schizophrenia. Annual Review of Clinical Psychology, 9, 465-497.

Murthy, N.V., Mahncke, H., Wexler, B.E., Maruff, P., Inamdar, A., Zucchetto, M., ... Alexander, R. (2012). Computerized cognitive remediation training for schizophrenia: An open label, multi-site, multinational methodology study. Schizophrenia Research, 139 (1-3), 87-91. doi: 10.1016/j.schres.2012.01.042

National Institute of Health and Clinical Excellence (NICE). (2009). Schizophrenia: Core interventions in the treatment and management of schizophrenia in primary and secondary care. NICE Clinical Practice Guideline, 82, 1-399. Retrieved from http:// www.nice.org.uk/CG82.

National Institute of Health and Clinical Excellence (NICE). (2014). Psychosis and schizophrenia in adults: Prevention and management. NICE Clinical Practice Guideline, 178, 1-684. Retrieved from http://www.nice.org.uk/CG178.

Nuechterlein, K.H., Green, M.F., Kern, R.S., Baade, L.E., Barch, D.M., Cohen, J.D., ... Marder, S.R. (2008). The MATRICS consensus cognitive battery, part 1: Test selection, reliability, and validity. American Journal of Psychiatry, 165(2), 203-213. doi: 10.1176/appi.ajp.2007.07010042

Paquin, K., Wilson, A.L., Cellard, C., Lecomte, T., \& Potvin, S. (2014). A systematic review on improving cognition in schizophrenia: Which is the more commonly used type of training, practice or strategy learning? BMC Psychiatry, 14, 139. doi: 10.1186/1471-244x-14-139

Parker, S., Foley, S., Walker, P., \& Dark, F. (2013). Improving the social cognitive deficits of schizophrenia: A community trial of Social Cognition and Interaction Training (SCIT). Australasian Psychiatry, 21(4), 346-351. doi: 10.1177/1039856213486305

Penades, R., Catalan, R., Pujol, N., Masana, G., Garcia-Rizo, C., \& Bernardo, M. (2012). The integration of cognitive remediation therapy into the whole psychosocial rehabilitation process: An evidence-based and person-centered approach. Rehabilitation Research and Practice, 2012, 386895. doi: 10.1155/2012/386895

Penades, R., Catalan, R., Salamero, M., Boget, T., Puig, O., Guarch, J., ... Gasto, C. (2006). Cognitive remediation therapy for outpatients with chronic schizophrenia: A controlled and randomized study. Schizophrenia Research, 87(1-3), 323-331. doi: 10.1016/j.schres.2006.04.019

Pillet, B., Morvan, Y., Todd, A., Franck, N., Duboc, C., Grosz, A., ... Amado, I. (2015). Cognitive remediation therapy (CRT) benefits more to patients with schizophrenia with low initial memory performances. Disability and Rehabilitation, 37(10), 846-853. doi: 10.3109/09638288.2014.946153

Pratt, S.I., Mueser, K.T., Smith, T.E., \& Lu, W. (2005). Self-efficacy and psychosocial functioning in schizophrenia: A mediational analysis. Schizophrenia Research, 78(2-3), 187-197. doi: 10.1016/j.schres.2005.02.014

Rauchensteiner, S., Kawohl, W., Ozgurdal, S., Littmann, E., Gudlowski, Y., Witthaus, H., ... Juckel, G. (2011). Testperformance after cognitive training in persons at risk mental state of schizophrenia and patients with schizophrenia. Psychiatry Research, 185(3), 334-339. doi: 10.1016/j.psychres.2009.09.003

Rossell, S.L., \& David, A.S. (1997). Improving performance on the WCST: Variations on the original procedure. Schizophrenia Research, 28(1), 63-76. doi: 10.1016/S0920-9964(97)00093-5

Royer, A., Grosselin, A., Bellot, C., Pellet, J., Billard, S., Lang, F., ... Massoubre, C. (2012). Is there any impact of cognitive remediation on an ecological test in schizophrenia? Cognitive Neuropsychiatry, 17(1), 19-35. doi: 10.1080/13546805.2011.564512

Saperstein, A., \& Kurtz, M.M. (2013). Current trends in the empirical study of cognitive remediation for schizophrenia. Canadian Journal of Psychiatry, 58(6), 311-318.

Sartory, G., Zorn, C., Groetzinger, G., \& Windgassen, K. (2005). Computerized cognitive remediation improves verbal learning and processing speed in schizophrenia. Schizophrenia Research, 75(2-3), 219-223. doi: 10.1016/j.schres.2004.10.004

Scheu, F., Aghotor, J., Pfueller, U., Moritz, S., Bohn, F., Weisbrod, M., ... Roesch-Ely, D. (2013). Predictors of performance improvements within a cognitive remediation program for schizophrenia. Psychiatry Research, 209(3), 375-380. doi: 10.1016/j.psychres.2013.04.015

Schmidt, S., Muhlan, H., \& Power, M. (2006). The EUROHIS-QOL 8-item index: Psychometric results of a cross-cultural field study. European Journal of Public Health, 16(4), 420-428. doi: 10.1093/eurpub/cki155

Schulz, K.F., Altman, D.G., \& Moher, D., Consort Group. (2010). CONSORT 2010 Statement: Updated guidelines for reporting parallel group randomised trials. BMC Medicine, 8, 18. doi: $10.1186 / 1741-7015-8-18$ 
Sharip, S., Michie, P., Schall, U., Drysdale, K., Case, V., Sankaranarayanan, A., ... Das, S. (2013). Generalization of cognitive training in an Australian sample of schizophrenia patients. Comprehensive Psychiatry, 54(7), 865-872. doi: 10.1016/j.comppsych.2013.03.015

Sheehan, D.V., Lecrubier, Y., Sheehan, K.H., Amorim, P., Janavs, J., Weiller, E., ... Dunbar, G.C. (1998). The Mini-International Neuropsychiatric Interview (M.I.N.I.): The development and validation of a structured diagnostic psychiatric interview for DSM-IV and ICD-10. Journal of Clinical Psychiatry, 59(Suppl 20), 22-33.

Subramaniam, K., Luks, T.L., Fisher, M., Simpson, G.V., Nagarajan, S., \& Vinogradov, S. (2012). Computerized cognitive training restores neural activity within the reality monitoring network in schizophrenia. Neuron, 73(4), 842-853. doi: 10.1016/ j.neuron.2011.12.024

van Heugten, C.M., Ponds, R.W., \& Kessels, R.P. (2016). Brain training: Hype or hope? Neuropsychological Rehabilitation, 26 (5-6), 639-644. doi: 10.1080/09602011.2016.1186101

Vauth, R., Corrigan, P.W., Clauss, M., Dietl, M., Dreher-Rudolph, M., Stieglitz, R.D., ... Vater, R. (2005). Cognitive strategies versus self-management skills as adjunct to vocational rehabilitation. Schizophrenia Bulletin, 31(1), 55-66. doi: 10.1093/schbul/ sbi013

Velikonja, D., Tate, R., Ponsford, J., McIntyre, A., Janzen, S., \& Bayley, M. (2014). INCOG recommendations for management of cognition following traumatic brain injury, Part V: Memory. Journal of Head Trauma Rehabilitation, 29(4), 369-386. doi: 10.1097/HTR.0000000000000069

Ventura, J., Subotnik, K.L., Ered, A., Gretchen-Doorly, D., Hellemann, G.S., Vaskinn, A., ... Nuechterlein, K.H. (2014). The relationship of attitudinal beliefs to negative symptoms, neurocognition, and daily functioning in recent-onset schizophrenia. Schizophrenia Bulletin, 40(6), 1308-1318. doi: 10.1093/schbul/ sbu002

Vinogradov, S., Fisher, M., \& de Villers-Sidani, E. (2012). Cognitive training for impaired neural systems in neuropsychiatric illness. Neuropsychopharmacology, 37(1), 43-76. doi: 10.1038/npp.2011.251

Vinogradov, S., Fisher, M., Warm, H., Holland, C., Kirshner, M.A., \& Pollock, B.G. (2009). The cognitive cost of anticholinergic burden: Decreased response to cognitive training in schizophrenia. American Journal of Psychiatry, 166(9), 1055-1062. doi: 10.1176/ appi.ajp.2009.09010017

Vita, A., De Peri, L., Barlati, S., Cacciani, P., Deste, G., Poli, R., ... Sacchetti, E. (2011). Effectiveness of different modalities of cognitive remediation on symptomatological, neuropsychological, and functional outcome domains in schizophrenia: A prospective study in a real-world setting. Schizophrenia Research, 133(1-3), 223-231. doi: 10.1016/j.schres.2011.08.010

Wallace, C.J., Liberman, R.P., Tauber, R., \& Wallace, J. (2000). The Independent Living Skills Survey: A comprehensive measure of community functioning of severely and persistently metally ill individuals. Schizophrenia Bulletin, 26(3), 631-658.

Wauchope, B., Terlich, A., \& Lee, S. (2016). Rel8: Demonstrating the feasibility of delivering an 8-week social skills program in a public mental health setting. Australasian Psychiatry, 24(3), 285-288. doi: 10.1177/1039856215612992

Woods, S.W. (2003). Chlorpromazine equivalent doses for the newer atypical antipsychotics. Journal of Clinical Psychiatry, 64(6), 663-667.

Wykes, T., Huddy, V., Cella, M., McGurk, S.R., \& Czobor, P. (2011). A meta-analysis of cognitive remediation for schizophrenia: Methodology and effect sizes. American Journal of Psychiatry, 168(5), 472-485.

Wykes, T., \& Reeder, C. (2005). Cognitive remediation therapy for schizophrenia: Theory and practice. London: Taylor \& Francis.

Wykes, T., Reeder, C., Huddy, V., Taylor, R., Wood, H., Ghirasim, N., ... Landau, S. (2012). Developing models of how cognitive improvements change functioning: Mediation, moderation and moderated mediation. Schizophrenia Research, 138(1), 88-93. doi: 10.1016/j.schres.2012.03.020

Wykes, T., Reeder, C., Landau, S., Everitt, B., Knapp, M., Patel, A., ... Romeo, R. (2007). Cognitive remediation therapy in schizophrenia: Randomised controlled trial. British Journal of Psychiatry, 190, 421-427. doi: 10.1192/bjp.bp.106. 026575

Wykes, T., \& Spaulding, W.D. (2011). Thinking about the future cognitive remediation therapy-What works and could we do better? Schizophrenia Bulletin, 37(Suppl 2), S80-S90. 